\title{
Failure of structural elements made of polymer supported composite materials during the multiyear natural aging
}

\author{
Pavel Blinkov ${ }^{*}$, Leonid Ogorodov ${ }^{1}$ and Peter Grabovyy ${ }^{2}$ \\ ${ }^{1}$ Peter the Great St.Petersburg Polytechnic University, Polytechnicheskaya, 29, St. Petersburg, \\ 195251, Russia \\ ${ }^{2}$ Moscow State University of Civil Engineering, Yaroslavskoe shosse, 26, Moscow, 129337, Russia
}

\begin{abstract}
Modern high-rise construction introduces a number of limitations and tasks. In addition to durability, comfort and profitability, projects should take into account energy efficiency and environmental problems. Polymer building materials are used as substitutes for materials such as brick, concrete, metal, wood and glass, and in addition to traditional materials. Plastic materials are light, can be formed into complex shapes, durable and low, and also possess a wide range of properties. Plastic materials are available in various forms, colors and textures and require minimal or no color. They are resistant to heat transfer and diffusion of moisture and do not suffer from metal corrosion or microbial attack. Polymeric materials, including thermoplastics, thermoset materials and wood-polymer composites, have many structural and non-structural applications in the construction industry. They provide unique and innovative solutions at a low cost, and their use is likely to grow in the future. A number of polymer composite materials form complex material compositions, which are applied in the construction in order to analyze the processes of damage accumulation under the conditions of complex nonstationary loading modes, and to determine the life of structural elements considering the material aging. This paper present the results of tests on short-term compression loading with a deformation rate of $\mathrm{v}=2 \mathrm{~mm} / \mathrm{min}$ using composite samples of various shapes and sizes.
\end{abstract}

\section{Introduction}

The mechanical properties of composite materials can be characterized using two approaches. In the first case, composite materials are considered as quasi-homogeneous (homogeneous), possessing isotropic deformation and strength properties in the case of volumetric disperse reinforcement, and possessing a certain type of anisotropy in the case of being reinforced with fibers, flat grids or fabrics. Usually models of an orthotropic or transversely isotropic bodies are adopted. Under this approach, the issue is about the

\footnotetext{
* Corresponding author: captainflint88@,gmail.com
} 
mechanical characteristics averaged in sufficiently large volumes. Another approach, which is incomparably more complex, but also more informative is to separately examine the mechanical properties of each phase with the subsequent forecasting of the properties of the entire composite. In this case, one more additional phase of the conjugation zone of the main phases is practically to be considered, for example, conjugation of matrices with reinforcing fibers. The phase boundaries are stress concentration zones, which play a particularly important role in the damage development of composite materials.

In respect to composites, which are often modeled by a homogeneous anisotropic body, the failure will be defined as the occurrence of any observed discontinuity.

Generalizations of the corresponding criteria for isotropic bodies (force, deformation and energy types and models in which the simultaneous occurrence of several damage processes is considered) were used to formulate the criteria for the failure of anisotropic materials in many works.

At present, the most common strength criteria of composites are the tensor polynomial failure criterion [2, 4] and the Goldenblat-Kopnov criterion [3].

The work [1] exposes the explanations for using the equation of force type damages in respect to orthotropic materials

$$
\Pi=\frac{\sigma(\tau)}{c}+\int_{0}^{\tau} f[\sigma(\theta)] d \theta
$$

where $\mathrm{c}$ is a constant. This correspondence was also reproduced in [5]. In accordance with the equation (1), the value $\mathrm{c}$ is relevant for the "instantaneous strength of materials", which becomes the material's property under rapid (instantaneous) loading, when the process of damage accumulation does not manage to appear yet. Equation (1) leads to the definition of the law of the "instantaneous" resistance change, which decreases in time with the damage accumulation. The correspondence is as follows [1]

$$
\sigma(\xi)=1-\int_{0}^{\xi} \sigma(\theta) d \theta
$$

which correlates with the functional exposed in [2], in order to determine the constricting resistance to the "instantaneous" discontinuity during the loading process. The formula (2) can be considered as a certain simple realization of this functional, at the same time the correlations (1) and (2) indicate that the method of the constricting "instantaneous" resistance and the method of kinematic equations are related in reference to the degree of damage to each other, they are alternative.

According to [3], the failure condition is as follows

$$
\sum_{k, l=x, y, z} a_{k l} \sigma_{k l}+\sqrt{\sum_{k, l, r, s=x, y, z} a_{k l r s} \sigma_{k l} \sigma_{r s}}=1,
$$

where the left-hand side can be represented by some reduced stress $\tilde{\sigma}$ in equation (1), where $c=1$. In order to determine the integrand $f[\sigma(\theta)]$ in (1), the allowance is made according to [3], which states that the static fatigue curves coincide for the case of different stressed states in the coordinates reduced stress - time to failure. After integrating at constant stresses $\tilde{\sigma}$ and developing the failure condition $\Pi=1$, we obtain

$$
1=\tilde{\sigma}\left(1+\int_{0}^{\xi} \frac{f[\sigma(\theta)] d \theta}{\tilde{\sigma}}\right)
$$

where $\Phi(\xi)=\int_{0}^{\xi} \frac{f[\sigma(\theta)] d \theta}{\tilde{\sigma}}=\int_{0}^{\xi} \varphi(\theta) d \theta, \Phi(0)=0$. 
Assuming that the equation of the static fatigue curve in case of uniaxial tension has the form $\tilde{\sigma}=A-B \lg \xi$, the rime function can be expressed as follows

$$
\Phi(\xi)=\int_{0}^{\xi} \frac{1}{A-B \lg \xi}-1, \varphi(\xi)=\frac{A}{2.303 \xi(A-B \lg \xi)^{2}}
$$

As a result for calculations, a kinematic equation can be written as where

$$
\Pi(\tau)=\tilde{\sigma}(\tau)+\int_{0}^{\tau} \tilde{\sigma}(\theta) \varphi(\theta) d \theta
$$

which can be used in the case of unsteady loading. It is to be recalled that $\tilde{\sigma}(\tau)$ is the reduced stress, which is defined as

$$
\tilde{\sigma}=\sum_{k, l=x, y, z} a_{k l} \sigma_{k l}+\sqrt{\sum_{k, l, r, s=x, y, z} a_{k l r s} \sigma_{k l} \sigma_{r s}}
$$

in the case of a linear stress state

$$
\tilde{\sigma}=\left(a_{x x}+\sqrt{a_{x x x x}}\right) \sigma_{x x}
$$

Coefficients at stresses for a composite are determined using the experimental data for the short-term loading under tension and compression in the directions of the main anisotropy axes, under a simple shear within these axes and axes rotated by an angle of $\pm 45^{\circ}$ referred to reference ones.

It is possible to give more complex failure criteria, but there is value to complicate the calculation model only in case it is indicated by the experiments. A number of works [1, 2, 6] have been devoted to the research of the scattered failure stage of composites. The general destruction process of structurally heterogeneous materials can be qualitatively divided into two stages, the first of which is associated with the disseminated accumulation of stable microcracks. The appearance conditions of macrocracks from micropores and microdefects were studied in the previously mentioned papers, and also in [7, 8]. According to researches $[12,15]$, the process of accumulation and coarsening of cracks was considered on the basis of the concentration criterion [14]. The papers [11, 13] are devoted to the statistical, thermodynamic and kinematic aspects of the transition from microcracks to macrodestruction. A variation of the phenomenological failure theory considering the orientation of defects and a complex stress state was developed in [10].

The case of an orthotropic material under a plane stressed state was considered. The expression for the reduced stress will in this case is as follows [1]:

$$
\tilde{\sigma}=a_{x x} \sigma_{x x}+a_{y y} \sigma_{y y}+\sqrt{a_{x x x x} \sigma_{x x}^{2}+a_{y y y y} \sigma_{y y}^{2}+a_{x y x y} \sigma_{x y}^{2}+a_{x x y y} \sigma_{x x} \sigma_{y y}},
$$

Coefficients at stresses for a material with sufficient brittleness under short-term loading are found using the experimental data according to the formulas:

$$
\begin{gathered}
a_{x x}=\frac{1}{2}\left(\frac{1}{\sigma_{u x x}^{+}}-\frac{1}{\sigma_{u x x}^{-}}\right) ; a_{x x x x}=\frac{1}{4}\left(\frac{1}{\sigma_{u x x}^{+}}-\frac{1}{\sigma_{u x x}^{-}}\right)^{2} ; \\
a_{y y}=\frac{1}{2}\left(\frac{1}{\sigma_{u y y}^{+}}-\frac{1}{\sigma_{u y y}^{-}}\right) ; a_{y y y y}=\frac{1}{4}\left(\frac{1}{\sigma_{u y y}^{+}}-\frac{1}{\sigma_{u y y}^{-}}\right)^{2} ; \\
a_{x y x y}=\frac{1}{4}\left(\frac{1}{\sigma_{u x y}^{2}}\right) ; a_{x x y y}=\frac{1}{8}\left[\left(\frac{1}{\sigma_{u x x}^{+}}-\frac{1}{\sigma_{u x x}^{-}}\right)^{2}+\left(\frac{1}{\sigma_{u y y}^{+}}-\frac{1}{\sigma_{u y y}^{-}}\right)^{2}-\left(\frac{1}{\sigma_{u x^{\prime} y^{\prime}}^{+}}-\frac{1}{\sigma_{u x^{\prime} y^{\prime}}^{-}}\right)^{2}\right] ;
\end{gathered}
$$

where $\sigma_{u x x}^{+}, \sigma_{u x x}^{-}, \sigma_{u y y}^{+}, \sigma_{u y y}^{-}$are the tensile and compressive strengths within main 
anisotropy axes; $\sigma_{u x y}$ is the simple shear strength within these axes; $\sigma_{u x^{\prime} y^{\prime}}^{+}, \sigma_{u x^{\prime} y^{\prime}}^{-}$are the strength limits for the simple shear within the axes $x^{\prime} y^{\prime}$, which are rotated to $x y$ axes by an angle of $+45^{\circ}$ or -45 respectively.

Further, it is necessary to have a static fatigue curve of any stress state at our disposal, for example, tension.

In the case of a biaxial stress state, the criterion can be written as

$$
\frac{\sigma_{1}^{2}}{\sigma_{1 P} \sigma_{1 c}}+\frac{\sigma_{2}^{2}}{\sigma_{2 p} \sigma_{2 c}}+\sigma_{1} \sigma_{2}\left[\frac{1}{\sigma_{1 P} \sigma_{2 c}}+\frac{1}{\sigma_{2 p} \sigma_{2 c}}-\frac{1}{\tau_{B}}\right]+\left(\frac{1}{\sigma_{1 P}}-\frac{1}{\sigma_{1 c}}\right)\left(\sigma_{1}+\sigma_{2}\right)=1,
$$

where $\tau_{\mathrm{B}}$ is the shear strength, which is independent of the sign of tangential stresses (designations are retained [1]). [6] as

Considering the assumption $\sigma_{1 P}=\sigma_{2 P}=\sigma_{P}, \sigma_{1 \mathrm{c}}=\sigma_{2 \mathrm{c}}=\sigma_{\mathrm{c}}$ criterion (7) can be written

$$
\frac{\sigma_{1}^{2}}{\sigma_{P} \sigma_{c}}+\frac{\sigma_{2}^{2}}{\sigma_{p} \sigma_{c}}+\sigma_{1} \sigma_{2}\left[\frac{2}{\sigma_{P} \sigma_{c}}-\frac{1}{\tau_{B}^{2}}\right]+\left(\frac{1}{\sigma_{P}}-\frac{1}{\sigma_{c}}\right)\left(\sigma_{1}+\sigma_{2}\right)=1,
$$

For certain correlations between the strength constants of the material, one can obtain

$$
\tau_{B}=\sqrt{\frac{\sigma_{P} \sigma_{c}}{3}}, \tau_{B}=\sqrt{\frac{\sigma_{P} \sigma_{c}}{2(1+\mu)}}, \tau_{B}=\frac{2 \sigma_{P} \sigma_{c}}{\sqrt{3}\left(\sigma_{P}+\sigma_{c}\right)}
$$

which require experimental determination. In the absence of these $\tau_{\mathrm{B}}$ values, the criterion of G.S. Pisarenko and A.A. Lebedeva is often used for checking

$$
\frac{\sigma_{P}}{\sigma_{c}} \sigma_{i}+\left(1-\frac{\sigma_{P}}{\sigma_{c}}\right) \sigma_{1}=\sigma_{P}
$$

The theoretical contour, which was constructed according to this criterion, deviates by no more than $13 \%$ from the experimental points of multiple polymeric materials. For $\chi=$ $\frac{\sigma_{P}}{\sigma_{c}}, 0 \leq \chi \leq 1$, which is true for most construction materials, the limiting surface is represented as a figure, which is equally inclined to the principal axes according to equation (9).

G.S. Pisarenko offered the condition for materials with structural heterogeneity

$$
\chi \sigma_{i}+(1-\chi) \sigma_{1} A^{1-J}=\sigma_{P},
$$

where $J=\frac{\sigma_{1}+\sigma_{2}+\sigma_{3}}{\sigma_{i}}$ is the stress state parameter; A is the parameter of the material structure. The value of parameter A can be determined using the torsional test data

$$
A=\frac{\varphi-\chi \sqrt{3}}{1-\chi}
$$

where $\varphi=\frac{\sigma_{P}}{\tau_{\mathrm{B}}}, \tau_{\mathrm{B}}$ is the limiting torsional stress. Condition (10) is intended for use in assessing the limiting states of fiber composites, glass-nylon composites.

\section{Materials and methods}

Composite materials K-211-2 and K-18-36 based on the phenol-formaldehyde resin with dispersed reinforcement consisting of wood powder particles and, in the other case, of kaolin particles, are used for structural elements, which work under conditions of different stress state types. The degree of filling of composites with particles was $30 \ldots 35 \%$. These composite materials are models of a large material class. Samples of composites were tested in their delivery condition, and a significant part of samples underwent natural aging under the 
conditions of a heated warehouse for 18-20 years. All tests were carried out under the same conditions.

Test materials were of the following dimensions (mm): $5 \times 5 \times 5 ; 8 \times 8 \times 8 ; 10 \times 10 \times 10, \mathrm{~d} / \mathrm{h}=$ $10 / 17.5 ; \mathrm{d} / \mathrm{h}=12 / 21$. Samples were set between the plates of the presses without lubricating the ends. Tensile tests were conducted using flat samples with a bearing length of $100 \mathrm{~mm}$, $25.4 \mathrm{~mm}$ wide and $1 \mathrm{~mm}$ thick. The tests of composites carried out by $\mathrm{Yu}$. Y. Loginov were conducted using samples with a diameter $\mathrm{D}=127 \mathrm{~mm}$, working part length $1=190 \mathrm{~mm}$, thickness $\mathrm{t}=6 \mathrm{~mm}$ under conditions of a linear and plane stress states.

The sample preparation was carried out as follows: 1) cutting of a prism-shaped specimen using precision circular saw 2) grinding of the samples with an in-house built fine mechanical abrasive grinder to achieve highly parallel opposite edges of the prism sample. Cylindrical shaped samples were manufactured on a lathe. The variation in flatness along the sample surfaces was measured to be in the range of $10 \mu \mathrm{m}$ using micrometer.

\section{Results of tests}

The results of tests on short-term compression loading with a deformation rate of $\mathrm{v}=2 \mathrm{~mm} / \mathrm{min}$ using K-211-2 and K-18-36 composite samples of various shapes and sizes (A is the cross-sectional area, $\mathrm{S}$ is the area of the free sample surface, $\mathrm{V}$ is the volume) are presented in Table 1 ( $\sigma_{u c}$ is the strength limit, $\varepsilon_{u c}$ is the deformation corresponding to the tensile strength, $\varepsilon_{r}$ is the residual deformation upon failure, $E_{c}$ is the elastic modulus).

In order to forecast the mechanical characteristics of the structural materials K-211-2 and $\mathrm{K}-18-36$ with larger sizes than tested ones, the results of the tests presented in Table 1 are processed in relative values depending on $\mathrm{A}, \mathrm{S}$, and $\mathrm{V}$.

Table 1. Dependence of mechanical characteristics on the size of the samples.

\begin{tabular}{|c|c|c|c|c|c|c|c|c|}
\hline Material & $\begin{array}{c}\text { Sample } \\
\text { dimensions, } \\
\mathrm{mm}\end{array}$ & $\begin{array}{c}\mathrm{A}, \\
\mathrm{mm}^{2}\end{array}$ & $\begin{array}{c}\mathrm{S}, \\
\mathrm{mm}^{2}\end{array}$ & $\begin{array}{c}\mathrm{V}, \\
\mathrm{mm}^{3}\end{array}$ & $\sigma_{u c}, M P a$ & $\varepsilon_{u c}$ & $\varepsilon_{r}$ & $E_{c}, M P a$ \\
\hline $\mathrm{K}-211-2$ & $5 \times 5 \times 5$ & 25 & 100 & 125 & 220.1 & 0.126 & 0.055 & 3110 \\
\hline $\mathrm{K}-211-2$ & $8 \times 8 \times 8$ & 64 & 256 & 512 & 225.2 & 0.154 & 0.082 & 3200 \\
\hline $\mathrm{K}-211-2$ & $10 \times 10 \times 10$ & 100 & 400 & 100 & 216.0 & 0.144 & 0.077 & 3070 \\
\hline $\mathrm{K}-211-2$ & $\mathrm{~d} / \mathrm{h}=10 / 17.5$ & 78,5 & 595 & 1374 & 199.6 & 0.082 & 0.041 & 4880 \\
\hline $\mathrm{K}-211-2$ & $\mathrm{~d} / \mathrm{h}=12 / 21$ & 113 & 791 & 2374 & 194.6 & 0.072 & 0.027 & 4280 \\
\hline $\mathrm{K}-18-36$ & $8 \times 8 \times 8$ & 64 & 256 & 512 & 156.8 & 0.072 & 0.018 & 2860 \\
\hline $\mathrm{K}-18-36$ & $\mathrm{~d} / \mathrm{h}=12 / 21$ & 113 & 791 & 2373 & 148.0 & 0.060 & 0.021 & 4080 \\
\hline
\end{tabular}

According to the data presented in Table 1, following analytical correlations are obtained:

$$
\begin{aligned}
& \lg \left(\sigma_{u c} / A\right)=a_{0}-b_{0} \lg A \\
& \lg \left(\sigma_{u c} / S\right)=a_{1}-b_{1} \lg S \\
& \lg \left(\sigma_{u c} / V\right)=a_{2}-b_{2} \lg V \\
& \lg \left(\varepsilon_{u c} \cdot 10^{4} / V\right)=a_{3}-b_{3} \lg V \\
& \lg \left(\varepsilon_{r} \cdot 10^{4} / V\right)=a_{4}-b_{4} \lg V \\
& \lg \left(E_{c} / V\right)=a_{5}-b_{5} \lg V
\end{aligned}
$$

where $\sigma_{u c}$ and $E_{c}$ values are expressed in $\mathrm{MPa}, \mathrm{A}$ in $\mathrm{mm}^{2}, \mathrm{~S}$ in $\mathrm{mm}^{2}, \mathrm{~V}$ in $\mathrm{mm}^{3}$, and the coefficients a and $\mathrm{b}$ for the analyzed composites at $v=2 \mathrm{~mm} / \mathrm{min}$ are presented in Table 2 . 
Table 2. Values of coefficients (at $v=2 \mathrm{~mm} / \mathrm{min}$ ).

\begin{tabular}{|c|c|c|c|c|c|c|c|c|c|c|c|c|}
\hline Material & $\mathrm{a}_{0}$ & $\mathrm{~b}_{0}$ & $\mathrm{a}_{1}$ & $\mathrm{~b}_{1}$ & $\mathrm{a}_{2}$ & $\mathrm{~b}_{2}$ & $\mathrm{a}_{3}$ & $\mathrm{~b}_{3}$ & $\mathrm{a}_{4}$ & $\mathrm{~b}_{4}$ & $\mathrm{a}_{5}$ & $\mathrm{~b}_{5}$ \\
\hline K-211-2 & 2.39 & 1.05 & 2.46 & 1.06 & 2.44 & 1.05 & 0.28 & 1.42 & 0.78 & 1.69 & 3.15 & 0.85 \\
\hline K-18-36 & 2.24 & 1.03 & 2.32 & 1.05 & 2.28 & 1.03 & 0.84 & 1.11 & - & - & 3.08 & 0.85 \\
\hline
\end{tabular}

In order to determine the $\mathrm{a}$ and $\mathrm{b}$ coefficients for the K-18-36 composite, analytical correlations were used, which are analogous to the correlations determined for the K-211-2 composite. The mechanical characteristics related to the cross-sectional area and to the free surface area of the sample depend on their shapes, while these characteristics, which are related to the volume of the samples (for given cross-sectional area to sample height ratios), do not depend on the shape and can be sufficiently accurate described by the dependences (13) - (16).

Dependencies (11) - (16) were used to predict the mechanical characteristics of composite samples of different sizes under uniaxial compression with a deformation rate of $\mathrm{v}=2$ $\mathrm{mm} / \mathrm{min}$.

The results of the calculations are given in Table 3, where the values $\sigma_{u c}^{A}$ and $\sigma_{u c}^{S}$ were determined from the dependences (11) - (12), and $\sigma_{u c}^{V}, \varepsilon_{u c}, \varepsilon_{r}, E_{c}$ values from (13) - (16).

Table 3. Mechanical characteristics of composite samples of different sizes.

\begin{tabular}{|c|c|c|c|c|c|c|c|}
\hline Material & $\begin{array}{c}\text { Sample } \\
\text { dimensions, } \\
\mathrm{mm}\end{array}$ & $\begin{array}{c}\sigma_{u c}^{A}, \\
\mathrm{MPa}\end{array}$ & $\begin{array}{c}\sigma_{u c}^{S}, \\
\mathrm{MPa}\end{array}$ & $\begin{array}{c}\sigma_{u c}^{V}, \\
\mathrm{MPa}\end{array}$ & $\varepsilon_{u c}$ & $\varepsilon_{r}$ & $E_{c}, \mathrm{MPa}$ \\
\hline $\mathrm{K}-211-2$ & $20 \times 20 \times 20$ & 181.9 & 185.2 & 175.7 & 0.044 & 0.012 & 5400 \\
\hline $\mathrm{K}-211-2$ & $50 \times 50 \times 50$ & 166.0 & 166.0 & 153.2 & 0.014 & 0.002 & 8200 \\
\hline $\mathrm{K}-211-2$ & $127 / 190 / 6$ & 166.8 & 141.4 & 143.9 & 0.008 & - & 9900 \\
\hline $\mathrm{K}-18-36$ & $5 \times 5 \times 5$ & 157.8 & 166.0 & 162.8 & 0.084 & - & 2460 \\
\hline $\mathrm{K}-18-36$ & $10 \times 10 \times 10$ & 151.4 & 154.8 & 153.8 & 0.068 & - & 3390 \\
\hline $\mathrm{K}-18-36$ & $\mathrm{~d} / \mathrm{h}=10 / 17.5$ & 152.4 & 152.4 & 151.6 & 0.064 & - & 3540 \\
\hline $\mathrm{K}-18-36$ & $20 \times 20 \times 20$ & 145.2 & 144.5 & 144.2 & 0.054 & - & 4630 \\
\hline $\mathrm{K}-18-36$ & $50 \times 50 \times 50$ & 137.4 & 131.8 & 132.4 & 0.044 & - & 6990 \\
\hline $\mathrm{K}-18-36$ & $127 / 190 / 6$ & 137.8 & 115.4 & 129.1 & 0.011 & - & 8420 \\
\hline
\end{tabular}

The results of calculating the mechanical characteristics from dependences (11) - (16) and the results of K-211-2 tests are compared in Table 4.

Table 4. Mechanical characteristics of K-211-2.

\begin{tabular}{|c|c|c|c|c|c|c|c|}
\hline $\begin{array}{c}\text { Sample } \\
\text { dimensions, } \\
\mathrm{mm}\end{array}$ & $\begin{array}{c}\sigma_{u c}^{A}, \\
\mathrm{MPa}\end{array}$ & $\begin{array}{c}\sigma_{u c}^{S}, \\
\mathrm{MPa}\end{array}$ & $\begin{array}{c}\sigma_{u c}^{\text {exp }}, \\
\mathrm{MPa}\end{array}$ & $\varepsilon_{u c}$ & $\varepsilon_{u c}^{\text {exp }}$ & $E_{c}, \mathrm{Mpa}$ & $\begin{array}{c}E_{c}^{\text {exp }}, \\
\mathrm{MPa}\end{array}$ \\
\hline $\mathrm{d} / \mathrm{h}=10 / 15$ & 187.3 & 186.9 & 171.8 & 0.0076 & 0.074 & 3990 & - \\
\hline $\mathrm{d} / \mathrm{h}=10 / 17.5$ & 187.3 & 185.4 & 201.3 & 0.070 & 0.098 & 4070 & 4440 \\
\hline
\end{tabular}

The tensile strength $\left(\sigma_{u t}\right)$ of composite samples K-211-2 and K-18-36, which underwent natural aging (up to 19 years), under uniaxial tension conditions with different deformation velocities $v$ (base velocity $\mathrm{v}=2 \mathrm{~mm} / \mathrm{min}$ ) is $46.06 \mathrm{MPa}$ and $37.70 \mathrm{MPa}$ respectively. After the delivery, the tensile strength of tubular samples of the K-211-2 composite was $22.5 \mathrm{MPa}$ and 127.6 MPa for uniaxial compression, and K-18-36 samples had 20 MPa and 85.8 MPa, respectively. After the tests of flat samples $(\mathrm{v}=2 \mathrm{~mm} / \mathrm{min})$ of the same composites in the delivery condition, $\sigma_{u t}=41.89 \mathrm{MPa}$ was obtained, $\sigma_{u c}=190.9 \mathrm{MPa}$ and $\sigma_{u t}=35.9 \mathrm{MPa}, \sigma_{u c}$ $=144.2 \mathrm{MPa}$. The strength of solid thin-walled samples $(\mathrm{t}=1 \mathrm{~mm})$ is approximately 1.7 
times higher than the strength of tubular samples made of the same material, but larger. We should notice the results of the strength characteristics of a composite sample batch having a circular spherical surface obtained by machining $(\mathrm{h}=21 \mathrm{~mm}, \mathrm{~d}=12 \mathrm{~mm}$, the smallest diameter of the cross section is $8.55 \div 9.9 \mathrm{~mm}$, the width of the groove is $6.5 \div 7 \mathrm{~mm}$ ). After the 19-year natural aging of the samples, the compressive strength at a deformation rate of $\mathrm{V}$ $=2 \mathrm{~mm} / \mathrm{min}$ was $\sigma_{u c}=196.2 \mathrm{MPa}$ for the composite K-211-2, which is substantially higher than one for the samples without machining. This fact can be explained by the peculiarity of the triaxial stress state affecting the central part of the sample.

Figures $1 \mathrm{a}$ and $1 \mathrm{~b}$ represent the limiting stress values and ultimate failure lines of composite materials K-211-2 and K-18-36, respectively. The results obtained by Yu. Y. Loginov are plotted with single points (o).

The processing of the experimental data was carried out according to the stress intensity $\sigma_{i}$, as well as to the equivalent stresses calculated using the Pisarenko-Lebedev criterion (line 1), also experimental and calculated values were defined using the Goldenblat-Kopnov criterion. In the first quadrant $\sigma_{1}>0, \sigma_{2}>0$, the samples of both composites show a lower strength than the limiting ones (line 1). Higher values of $\sigma_{3}$ (compressive stresses) in experiments led to greater strength of the composites.

An attempt was made in order to estimate the limiting values using the GoldenblatKopnov criterion, where the calculation values of the limiting shear stresses were adopted according to the dependences

$$
\tau_{B}=\sqrt{\frac{\sigma_{P} \sigma_{c}}{3}}, \tau_{B}=\frac{2 \sigma_{P} \sigma_{c}}{\sqrt{3}\left(\sigma_{P}+\sigma_{c}\right)},
$$

According to the Goldenblat-Kopnov criterion for the stresses $\sigma_{1}=2 \sigma_{2}$ and the composite K-211-2, it was obtained 1.036 and 0.888 , for the stresses $\sigma_{1}=\sigma_{2}$ we have 1.124 and 0.928 , for the composite K-18-36 it is 0.928 and $0.805,0.860$ and 0.604 in comparison with the limiting condition which equal to 1.0 .

Limiting curves (2) of the tubular structural element $(D=127 \mathrm{~mm}, t=6 \mathrm{~mm}, 1=190 \mathrm{~mm})$ were predicted according to Pisarenko-Lebedev criterion for a period of 20-25 years (are marked on the Figures $1 \mathrm{a}$ and $1 \mathrm{~b}$ with the individual points $(\Delta)$ of the limit curve), taking into account the natural aging effect of composites and the scale factor.

Forecasting limiting curves (2) are represented according to the Pisarenko-Lebedev criterion of structural elements of smaller dimensions in the investigated scale range (in particular, $A=113 \mathrm{~mm}^{2}, \mathrm{~S}=595 \mathrm{~mm}^{2}, \mathrm{~V}=2373 \mathrm{~mm}^{2}$ ).

Figures $2 \mathrm{a}$ and $2 \mathrm{~b}$ represent the isochronous ultimate failure lines of K-211-2 and K-1836 composites under the conditions of a plane stress state and a prolonged steady loading during the one day, ten and one hundred days.

The significant problem is the calculation of the composite damage level under nonstationary (stepwise in particular) regimes of static and cyclic loading in plane stress conditions. The equivalent $\left(\sigma_{e q}\right)$ stresses (acceptable for the planning of nonstationary loading regimes) are determined according to the Pisarenko-Lebedev criterion.

For the K-211-2 it is adopted as follows:

$$
\begin{array}{ll}
\text { 1. } & \sigma_{1}=31.02 \mathrm{MPa}, \sigma_{2}=15.51 \mathrm{MPa}, \sigma_{e q} \approx 30 \mathrm{MPa} \\
\text { 2. } & \sigma_{1}=31.02 \mathrm{MPa}, \sigma_{2}=15.51 \mathrm{MPa}, \sigma_{e q} \approx 30 \mathrm{MPa} \\
3 . & \sigma_{1}=31.02 \mathrm{MPa}, \sigma_{2}=15.51 \mathrm{MPa}, \sigma_{e q} \approx 30 \mathrm{MPa} \\
\text { 4. } & \sigma_{1}=31.02 \mathrm{MPa}, \sigma_{2}=15.51 \mathrm{MPa}, \sigma_{e q} \approx 30 \mathrm{MPa} \\
\text { 5. } & \sigma_{1}=31.02 \mathrm{MPa}, \sigma_{2}=15.51 \mathrm{MPa}, \sigma_{e q} \approx 30 \mathrm{MPa} \\
6 . & \sigma_{1}=31.02 \mathrm{MPa}, \sigma_{2}=15.51 \mathrm{MPa}, \sigma_{e q} \approx 30 \mathrm{MPa}
\end{array}
$$

For the composite $\mathrm{K}-18-36, \sigma_{e q}=30 \mathrm{MPa}$ is adopted. The parameter $\chi=\frac{\sigma_{u t}}{\sigma_{u c}}=\frac{\sigma_{P}}{\sigma_{c}}$ for $\mathrm{K}$ $211-2$ is 0.237 , for the $\mathrm{K}-18-36$ composite it is 0.255 . 


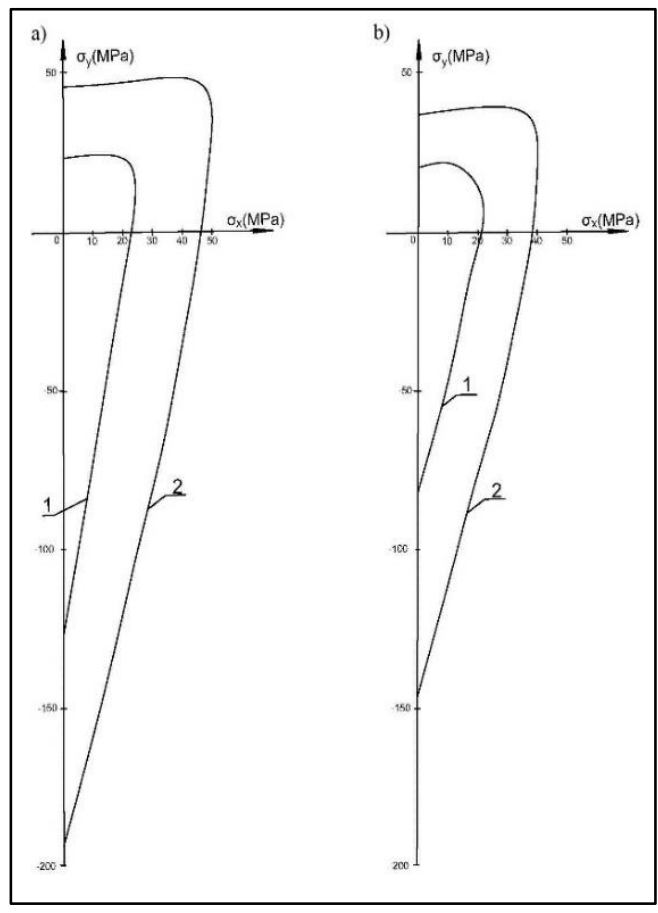

Figure 1. Limiting stress values and ultimate failure lines of composite materials K-2112(1a) and K-18-36(1b).

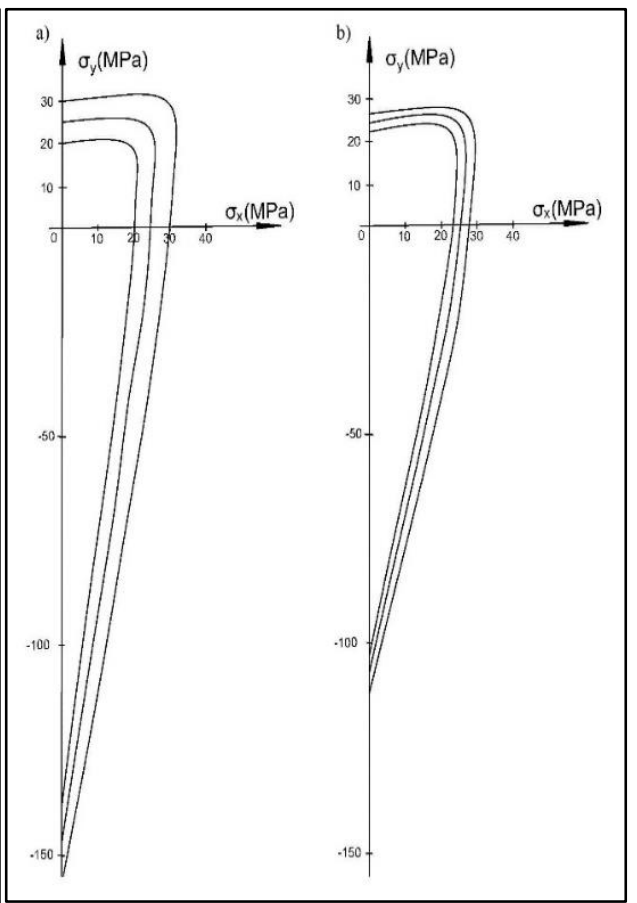

Figure 2. Isochronous ultimate failure lines of K-211-2(2a) and K-18-36(2b).

The values of stresses, loading and unloading (rest) periods, as well as calculated damage levels of composites under nonstationary loading regimes (where the order of loads (1) - (6) can be arbitrary) are exposed in Table 5 and Table 6 . The version of the kinetic equation was used (4)

$$
\Pi=\int_{0}^{\tau} \tilde{\sigma}_{e q} \sigma(\theta) K(\tau-\theta) \mathrm{d} \theta, \Pi(\tau)=\tilde{\sigma}(\tau)+\int_{0}^{\tau} \tilde{\sigma}(\theta) \varphi(\theta) \mathrm{d} \theta,
$$

where $\tilde{\sigma}_{e q}$ is the reduced equivalent stress, $K(\tau-\theta)$ is the nucleus

Table 5. Loading regimes and the forecasted damage level of the K-211-2 composite.

\begin{tabular}{|c|c|c|c|c|c|}
\hline Regime & Grade of load & $\sigma_{e q}, \mathrm{MPa}$ & $\tau$, hour & $\tau_{0}$, hour & $\Pi$ \\
\hline \multirow{5}{*}{1} & 1 & 20 & 8 & - & 0.009 \\
\hline & 2 & 30 & 8 & 16 & 0.017 \\
\hline & 3 & 20 & 8 & - & 0.030 \\
\hline & 4 & 30 & 8 & - & 0.945 \\
\hline & & & & & Total:1.001 \\
\hline \multirow{5}{*}{2} & 1 & 20 & 8 & - & 0.001 \\
\hline & 2 & 30 & 8 & 8 & 0.020 \\
\hline & 3 & 20 & 8 & - & 0.030 \\
\hline & 4 & 30 & 8 & - & 0.945 \\
\hline & & & & & Total:1.007 \\
\hline \multirow{6}{*}{3} & 1 & 30 & 8 & - & 0.010 \\
\hline & 2 & 20 & 8 & 16 & 0.007 \\
\hline & 3 & 30 & 8 & - & 0.017 \\
\hline & 4 & 20 & 8 & 16 & 0.014 \\
\hline & 5 & 30 & 8 & - & 0.945 \\
\hline & & & & & Total:0.993 \\
\hline 4 & 1 & 30 & 8 & - & 0.028 \\
\hline
\end{tabular}




\begin{tabular}{|c|c|c|c|c|c|}
\hline \multirow{4}{*}{} & 2 & 20 & 8 & - & 0.030 \\
\cline { 2 - 6 } & 3 & 30 & 8 & - & 0.945 \\
\cline { 2 - 6 } & & & & & Total: 1.003 \\
\hline \multirow{3}{*}{5} & 1 & 20 & 36.5 & - & 0.096 \\
\cline { 2 - 6 } & 2 & 30 & 4 & - & 0.904 \\
\hline \multirow{3}{*}{6} & 1 & & & & Total:1.000 \\
\cline { 2 - 6 } & 2 & 25 & 200 & - & 0.003 \\
\cline { 2 - 6 } & & & & & 0.994 \\
\hline
\end{tabular}

Table 6. Loading regimes and the forecasted damage level of the K-18-36 composite.

\begin{tabular}{|c|c|c|c|c|c|}
\hline Regime & Grade of load & $\sigma_{e q}, \mathrm{MPa}$ & $\tau$, hour & $\tau_{0}$, hour & $\Pi$ \\
\hline \multirow{5}{*}{1} & 1 & 22 & 8 & - & 0.005 \\
\hline & 2 & 27 & 8 & 16 & 0.007 \\
\hline & 3 & 22 & 8 & - & 0.016 \\
\hline & 4 & 27 & 8 & - & 0.969 \\
\hline & & & & & Total:0.997 \\
\hline \multirow{5}{*}{2} & 1 & 22 & 8 & - & 0.006 \\
\hline & 2 & 27 & 8 & - & 0.008 \\
\hline & 3 & 22 & 8 & - & 0.016 \\
\hline & 4 & 27 & 8 & - & 0.969 \\
\hline & & & & & Total:0.999 \\
\hline \multirow{3}{*}{3} & 1 & 25 & 1 & - & 0.036 \\
\hline & 2 & 30 & 0.25 & - & 0.979 \\
\hline & & & & & Total:1.015 \\
\hline \multirow{3}{*}{4} & 1 & 30 & 0.5 & - & 0.0001 \\
\hline & 2 & 25 & 250 & - & 0.996 \\
\hline & & & & & Total:0.996 \\
\hline \multirow{4}{*}{5} & 1 & 27 & 8 & - & 0.012 \\
\hline & 2 & 22 & 8 & - & 0.016 \\
\hline & 3 & 27 & 8 & - & 0.969 \\
\hline & & & & & Total:0.997 \\
\hline \multirow{6}{*}{6} & 1 & 27 & 8 & 8 & 0.003 \\
\hline & 2 & 27 & 8 & 8 & 0.005 \\
\hline & 3 & 27 & 8 & 8 & 0.007 \\
\hline & 4 & 27 & 8 & 8 & 0.012 \\
\hline & 5 & 27 & 8 & - & 0.969 \\
\hline & & & & & Total:0.996 \\
\hline
\end{tabular}

\section{Discussion}

Manufacturing of elements made of materials and structural elements after long-term storage, re-opening, re-profiling, rejection and exploitation is economically beneficial. Recycling into secondary raw materials and then into elements requires significant expenses, and sometimes such a process is impossible. Burial or destruction of unused structural elements leads to negative environmental impacts. The use of elements made from stored and exploited materials and structural elements requires an assessment of changes of their properties, in particular of residual strength. The development of requirements for the rejection and decommissioning of elements and structures according to the residual mechanical properties of materials is a vital question. Another issue is the evaluation of the damage level and calculation of the resource of materials and structural elements under conditions of complex operating modes (loading regimes).

\section{Conclusion}

Unique experimental data on the mechanical characteristics of composite materials K-211-2 
and K-18-36, which have undergone 18-20 years of natural aging, are obtained.

Calculated dependences, which allow to consider the effect of a scale factor on the mechanical characteristics of composites, are determined.

The results of composite tests in the plane stress state are compared with the calculations based on the Pisarenko-Lebedev and Goldenblat-Kopnov criteria, which are recommended for evaluating the strength for the flat stressed state of composites.

Failure limit lines for tubular composite structural elements are constructed, considering the scale factor in the investigated range of sizes and natural aging of materials.

Nonstationary regimes of disproportionate loading of composites were developed in order to estimate the operational life of composites, as well as to estimate the damage level at the failure time under conditions of plane stress.

\section{Acknowledgments}

The authors would like to thank prof. Stolyarov O.N. for helping with the experiments.

\section{References}

1. O. A. Kurakova I. S. Sychev and M. A. Isaev 2010 Nedvizhimost': Ekonomika, upravlenie 1 pp 92-95

2. P. P. Zueva 2014 Aktual'nye problem stroitel'stva, ecologii I enegosberezheniya v usloviyah zapadnoj sibiri 1 pp 98-104

3. S. V. Sargasyan and A. A. Hromenkova 2016 Nuchnoe obozrenie 18 pp 36-39

4. D. N. Gotina and U. G. Tkachenko 2015 Novye idei novogo veka: materialy mezhdunarodnogo nauchnoj konferencii FAD TOGU 2 pp 15-20

5. I. P. Nikolaeva L. I. Ogorodov and E. L. Yakovleva 2017 Stroitel'stvo unikal'nyh zdanij $i$ sooruzhenij 3 pp 8-17

6. M. N. Stepnov S. L. Chernyshev I. E. Kovalev and A. V. Zinin 2010 Monografiya Izdatel'skij centr "Tekhnologiya mashinostroeniya" (Moskva) $256 \mathrm{pp}$

7. V. V. Nesmelov 1993 Fizika goreniya I vzryva 29 pp 23-28

8. R. V. Ishchenko S. V. Avdeichik E. V. Ovchinnikov and V. A. Struk 2014 Vesnik grodzenskaga dzyarhanaga universiteta im. Yanki Kupaly 1 pp 63-68

9. K. Cirule 2008 Mekhanika kompozitnyh materialov 3 pp 463-468

10. S. K. Golyshko 2005 Vychislitel'nye tekhnologii 1 pp 134-135

11. M. I. Balzannikov and A. A. Mikhasek 2014 Procedia Engineering 91 pp 183-187

12. S. Chadiarakoua and P. Antoniadoub 2017 Procedia Environmental Sciences 38 pp 830-835

13. S. Ramakrishnan X. Wang J. Sanjayan and J. Wilson 2011 Applied energy $7 \mathrm{pp}$ $1515-1526$

14. E. A. Nekliudova A. S. Semenov B. E. Melnikov S. G.Semenov 2014 Civil Engineering 3 pp 25-39

15. К. B. Broberg 1982 Engineering Fracture Mechanic 4 pp 497 - 515 